\title{
Cuando los mitos tienen un fondo de historicidad: El origen lacustre de los Incas primordiales
}

\author{
Rodolfo Cerrón-Palomino ${ }^{1}$
}

\begin{abstract}
"Varias y diversas cosas y graciosas fábulas cuentan los indios del aparecimiento de los primeros yngas y de la manera con que entraron en la ciudad del Cuzco y la conquistaron y poblaron, sin que en este caso pueda haber cosa cierta ni determinada. La más general y común opinión más recibida entre ellos es que el primer Inga se llamó Manco Capac, aunque también a éste algunos le hacen el último de los hermanos Ingas. Pero sea lo que fuere, yo seguiré en esta historia aquello que con más probabilidad he podido sacar y averiguar."
\end{abstract}

Murúa ([1613] 1987: I, II, 48-49)

\section{Resumen}

Los relatos recogidos por los cronistas españoles de los siglos XVI y XVII sobre los incas han sido tildados, en buena parte, como meras fábulas, carentes de historicidad. En la presente ponencia intentamos demostrar que, gracias al trabajo interdisciplinario, particularmente de la lingüística, la historia, la arqueología, e incluso la genética, algunos de tales relatos, subestimados por la historiografía canónica, constituyen narraciones que contienen un fondo de verosimilitud. Ello es particularmente cierto en el caso del origen lacustre de los incas (procedentes del Titicaca) y de su lengua ancestral, que no fue la quechua ni la aimara sino la puquina.

Palabras clave: Heurística. Onomástica. Colla. Puquina. Callahuaya.

\begin{abstract}
Narratives about the Incas recorded by the XVI-XVIIth Spanish chroniclers have been considered, in part at least, as mere fables, devoid of historicity. In the present address I try to demonstrate that, thanks to the interdisciplinary work, mainly linguistics, ethnohistory, archaeology, and even genetics, some of the narratives, underestimated by the Inca canonical historiography, actually contain a history full of realism and veridiction. This is particularly true in the case of the lacustrine origin (from Lake Titicaca provenience) of the Incas and their ancestral tongue, which was neither Quechua nor Aymara but Puquina.
\end{abstract}

Keywords: Heuristics. Onomastics. Colla. Puquina. Callahuaya.

1 Pontificia Universidad Católica del Perú. 


\section{Propósito}

En la presente contribución nos ocuparemos de un tema muy conocido dentro de la historiografía incaica: el origen altiplánico - lacustre más específicamente - de los ancestros de los incas, emergiendo del lago Titicaca y marchando en dirección del Cuzco, según las versiones recogidas por los cronistas. Tales versiones han sido tomadas, según expresión de sus propios averiguadores, como "niñerías" o "desatinos" desprovistos de todo realismo. La historiografía contemporánea no ha sido menos condescendiente con ellas al restarles toda historicidad, confinándolas al reino de la fantasía, es decir del mito. De esta manera, no solo se les ha regateado todo carácter de veridicción, llegándose incluso a sostener que, en verdad, los soberanos cuzqueños habrían inventado tales relatos en un afán por apoderarse de la tradición de sus vencidos, una práctica por lo demás muy socorrida entre los vencedores. En lo que sigue trataremos de demostrar que, contrariamente a lo señalado por tales corrientes de opinión, existen indicios seguros de carácter lingüístico, particularmente de carácter onomástico, que parecen corroborar lo señalado por los mitos fundacionales de los incas. Tales evidencias se ven respaldadas, además, por la arqueología, y más recientemente por la genética, disciplinas ambas que demuestran la existencia de una relación muy estrecha entre las sociedades de la región del Titicaca y del valle del Cuzco desde tiempos que remontan por lo menos al Período Intermedio Temprano (200-550 d.C.). De esta manera, la investigación en lingüística histórica relativa a los orígenes del imperio incaico estaría probándonos que los mitos de origen, considerados por la historiografía canónica como fabulaciones carentes de toda lógica interna, contienen en verdad un fondo de historicidad.

\section{Mito e historia}

Refiere Ramos Gavilán, el cronista del santuario de Copacabana, que el inca Huaina Capac introdujo una serie de reformas relacionadas con las prácticas del culto a la divinidad suprema del lago Titicaca - el Sol - . Una de ellas fue el traslado del lugar de los sacrificios, inicialmente efectuados en la isla llamada precisamente del Sol, a otra llamada < Paapiti> (la de los "Dos Atajos"), que, "siendo todas las demás ayrosas [ventosas], es ésta muy serena, y por esta causa fue muy celebrada del Inga Guaynacapac" ( $c f$. Ramos Gavilán [1621] 1988: I, XXX, 182-183). Hecho el traslado, el lugar se convierte entonces en el adoratorio preferido del inca, adquiriendo de inmediato tanta fama que la multitud de peregrinos acudía a ella, "no obstante la dificultosa navegación y riesgo que en ella suele aver" (cf. op. cit., ibídem, 183). Sin embargo, el regocijo del soberano duraría muy poco tiempo. Y es que, según continúa narrándonos el mencionado cronista, 
el primer invierno sucedió ser de tantas aguas, que nuestra laguna subió lo que bastó para anegar la isleta, y cubrirla, de modo que se perdió de vista. En estremo sintió el Inga este caso, y aun lo tuvo a siniestro agüero, por ser cosa nueva, y nunca imaginada, la qual de tal suerte embraveció el pecho deste tirano, que mandó con gran rigor se buscasse el parage de ella, mandando no cesasse el sacrificio, por más que la dificultad, y riesgo, lo pretendiessen estorvar. Para lo qual él, y todos los que buscavan su gusto hallaron traça, y fue hazer unas caxuelas de piedra bien labradas con sus compuertas, en las quales ponían la ofrenda y sacrificio, y con una maromas las dexavan caer en el lugar donde antes sacrificaban a pie enjuto (cf.op. cit, I, XXX:183).

Pues bien, de acuerdo con el estereotipo mencionado, no debe extrañar que el relato del inca ordenando fondear las ofrendas votivas en el lugar donde él pensaba que estaba la isla sumergida bajo las aguas fuera tomado por los historiadores del área andina, acostumbrados a leer con escepticismo las narraciones amerindias, como una "fábula" más de las muchas que recoge el historiador de labios de sus informantes de la zona². Sucedió, sin embargo, que a inicios de la década del noventa del siglo pasado se le ocurrió a un equipo de investigadores integrado por arqueólogos e historiadores realizar trabajos de prospección subacuática precisamente en los alrededores del lugar donde se suponía que había realizado sus sacrificios y ofrendas el inca Huaina Capac (cf. Ponce Sanginés/Reinhard 1992). Lo asombroso fue que el trabajo bajo las aguas pronto dio frutos inesperados, pues los investigadores encontraron, luego de cerca de cinco siglos de estar sumergidas en las profundidades del lago, las "caxuelas de piedra bien labradas" con los contenidos votivos intactos, tal como puede apreciarlas actualmente quienquiera que visite el museo de sitio de la Isla del Sol. De esta manera, aquello que hasta entonces parecía un relato puramente fantástico, cobraba súbitamente un realismo a toda prueba a los ojos de los incrédulos, es decir develaba su plena historicidad. Hechos como este, sobra decirlo, debieran constituir una llamada de atención a quienes, como la mayoría de los historiadores y arqueólogos del mundo andino, suelen mostrarse renuentes ante la potencial veridicción de algunos de los relatos transmitidos por los cronistas del siglo XVI y XVII ( $c f$. Gutiérrez Estévez 2001). Sin embargo, parece olvidarse que algo más de una centuria previa el arqueólogo aficionado Heinrich Schliemann, libro de la Ilíada en manos, descubría precisamente el tesoro de Príamo, el legendario rey de Troya, demostrando ante el mundo

2 Conviene señalar, de entrada, que la subida de las aguas del lago y el consiguiente anegamiento de la isla a que hace referencia el historiador guamanguino se corrobora con los estudios paleohidrológicos del Titicaca, según los cuales entre 1400 y 1500 d.C. se produce un ascenso de la superficie de las aguas en algunos metros más de los que actualmente presenta ( $c f$. Bouysse-Cassagne 1991: Cuadro 1). 
entero que el relato homérico, en un principio transmitido oralmente, tenía un fondo de verdad histórica. Pero, naturalmente, para nuestros estudiosos que operan bajo esquemas occidentales, los relatos míticos europeos parecieran tener más historicidad que los de los pueblos amerindios.

Por cierto, las observaciones hechas hasta aquí no constituyen ninguna exageración para quien esté medianamente familiarizado con la historiografía del pasado incaico. Y así, por mencionar un solo ejemplo de los varios que podríamos traer a cuento, las versiones ofrecidas por los cronistas respecto a la guerra de los chancas poniendo en apuros a los incas han sido tildadas por los historiadores de "mitos disfrazados de historia" ( $c f$. Zuidema 1977, Duviols 1979) o de discursos narrativos carentes de todo respaldo material, vale decir arqueológico ( $c f$. Santillana 2002, Bauer et al. 2010).

En las secciones que siguen buscaremos demostrar que por lo menos algunos de tales "mitos", considerados como narraciones incoherentes, poseen en verdad un fondo histórico, y que solo aguardan, para ser interpretados como hechos verídicos, el trabajo de lingüistas históricos y arqueólogos desprejuiciados conceptual y metodológicamente. De manera específica, intentaremos probar que los relatos del origen lacustre de los ancestros de los incas se ven respaldados por los hallazgos recientes de los lingüistas, arqueólogos y genetistas del área andina que coinciden en señalar vínculos estrechos entre los antiguos pueblos del Titicaca y del valle del Cuzco.

\section{La tercera entidad idiomática}

Los estudios de lingüística histórica del área andina, iniciados en la década del sesenta del siglo pasado, además de postular la reconstrucción de las formas ancestrales del quechua y del aimara (sus proto-idiomas respectivos) y de trazar la evolución de éstos a partir de sus prototipos establecidos, tuvieron la virtud de desbaratar algunas falacias que formaban parte del saber consagrado tanto en los ambientes profanos como en los medios académicos, en especial en el de las ciencias histórico-sociales.

En efecto, dos de tales falacias profundamente arraigadas tenían que ver, por un lado, con el origen cuzqueño del quechua, y por el otro, con la procedencia altiplánica del aimara. En términos socio-culturales e históricos, a su vez, las lenguas mencionadas eran asociadas con los fundadores del imperio incaico y con los creadores de la civilización de Tiahuanaco. Sin embargo, en abierto rechazo de tales presupuestos, los estudios diacrónicos del quechua y del aimara parecían probar que, contrariamente a lo que se pensaba, tanto el quechua como el aimara tenían un origen centro-andino, localizable, aproximadamente, en la sierra y en la costa centro-sureñas del actual territorio peruano (cf. Torero [1970] 1972, Hardman [1966] 1975, Parker 1972). Quedaban descartadas, en consecuencia, la atribución del quechua a 
los incas y la asociación del aimara a los tiahuanaquenses. Al mismo tiempo, una vez zanjado su deslinde con el uro (idioma de los "hombres de agua", moradores exclusivos de los lagos y las islas de la región), se reivindicaba la lengua puquina - la "tercera lengua general" del antiguo Perú - como el idioma de la civilización lacustre. Posteriormente se demostraría, sobre la base de evidencias lingüísticas y documentales, que el aimara, llegado al valle del Cuzco procedente de la sierra centro-sureña, sería nada menos que la lengua oficial de los incas de la llamada dinastía mítica (cf. Cerrón-Palomino 2013: II-1).

Pues bien, dentro del cuadro de acontecimientos esbozado, surgía ahora un nuevo problema a encarar. En efecto, si los soberanos cuzqueños habían aprendido el aimara procedente de la región ayacuchana, ¿cuál habría sido la lengua materna de sus ancestros? Descartados el quechua y el aimara como candidatos, quedaba la tercera "lengua general", es decir la puquina, como el posible idioma de los fundadores de la civilización incaica. Se imponía entonces la demostración respectiva, pero para ello, a diferencia de lo que ocurre para con las otras dos lenguas, distábamos lejos de contar con evidencias lingüísticas y documentales medianamente solventes, comenzando por el hecho de que el puquina no solo es lengua muerta desde por lo menos la segunda mitad del siglo XIX sino que ni siquiera estamos seguros de que fuera objeto de registro gramatical y léxico. No obstante ello, como veremos, creemos que es posible demostrar, gracias al trabajo interdisciplinario, la plausibilidad de la hipótesis adelantada.

\section{Materiales puquinas}

No obstante haber sido reconocido como "lengua general" por el virrey Toledo según ordenanza expedida en Arequipa en 1575 ( $c f$. Toledo [1575] 1989: Vol. II:97-100), el puquina no parece haber sido objeto de registro y codificación, como lo fueron el quechua y el aimara. Es cierto que la bibliografía colonial consigna el dato acerca de la existencia, con fecha de 1590, de una gramática y de un léxico, atribuidos a Alonso de Barzana, eximio jesuita lenguaraz ( $c f$. De la Viñaza [1892] 1977:45). Sin embargo, lo cierto es que dicho material no ha sido localizado en ningún lugar, por lo que se duda incluso de su verdadera existencia.

No habiendo, pues, materiales lingüísticos propiamente dichos de la lengua, lo único que se tiene a la mano son los 26 textos religiosos de variada extensión, compilados y publicados por el franciscano Jerónimo de Oré en su monumental obra pastoral de naturaleza políglota ( $c f$. Oré 1607). Fuera de los materiales léxicos espulgados de tales textos, y que no ascienden sino a poco más de 250 términos ( $c f$. de la Grasserie 1894:12-21, Torero 1987:364370 ), no contamos para la lengua con mayores datos de naturaleza directa. 
Alguna evidencia indirecta la podemos encontrar en el callahuaya, la lengua secreta de los curanderos itinerantes de Charazani (Bolivia), que acusa un buen porcentaje de vocablos de origen puquina ( $c f$. Stark 1972); pero también, en menor medida y en forma insospechada, en el vocabulario del aimara recogido por Bertonio ([1612] 1984); y, finalmente, en proporción mucho menor aún, en el léxico disponible del uro-chipaya ( $c f$. Cerrón-Palomino y Ballón Aguirre 2011). En estas dos últimas instancias, en especial en el de la primera, la identificación de voces atribuibles al puquina como efecto de la influencia de esta lengua sobre aquéllas, se hace por descarte, cuando no por la existencia de dobletes léxicos, en cuyo caso uno de los pares resulta identificable como extraño a la lengua receptora. A falta de mayores datos que faciliten el trabajo de filiación de la tercera lengua como una variedad particular del puquina, el lingüista histórico puede recurrir también, y con algún provecho, al estudio de la onomástica, concretamente la correspondiente a la de los nombres propios tanto de lugar (topónimos) como institucionales vinculados al incario, y cuya identificación a partir del quechua o del aimara, en los documentos coloniales o en el terreno, resulta poco menos que imposible. Por lo demás, en esta labor de reconocimiento e identificación del léxico atribuible al puquina resulta imprescindible, como poderosa herramienta heurística, el conocimiento de los fragmentos de gramática de la lengua, tal como éstos han venido siendo inferidos a partir de los textos pastorales registrados por el criollo huamanguino Oré (ver, recientemente, Adelaar y van de Kerke 2009).

\section{El "lenguaje particular" de los incas}

Como se sabe, la documentación colonial nos proporciona información acerca del uso exclusivo, por parte de la nobleza imperial cuzqueña, de un "lenguaje divino", para emplear la expresión empleada por el Inca Garcilaso ([1609] 1943: VII, I, 88). Una de tales referencias, la más temprana y exenta de toda sospecha, la encontramos en la "Relación correspondiente a la Villa Rica de Oropesa y minas de Guancavelica" de don Rodrigo Cantos de Andrada, en la que se llama la atención sobre el mencionado idioma particular. Nos dice, en efecto, el funcionario aludido, que

En este reino hay mucha diferencia en los naturales de lenguas; pero en todo él los caciques y principales de los repartimientos tenían la obligación de saber la lengua general que llaman quechua, para saber y entender lo que se les mandaba de parte del inga, y para que, yendo a su corte, la entendiesen sin intérprete; y entre el mismo inga y su linaje y orejones hablaban otra, y ésta ningún cacique ni demás personas de su reino tenían licencia para aprendella ni vocablo della (énfasis agregado; cf. Cantos de Andrada [1586] 1965:307). 
Siendo dicha lengua particular, "diferente de la quichua y de la aymara", según se apura en precisarnos el cronista Murúa ([1613] 1987: II, XII, 377), resulta natural que postulemos el puquina como la entidad arcana referida. Si ahora, buscando armar el rompecabezas, asociamos el origen altiplánico de esta lengua con la procedencia lacustre de los ancestros de los incas, según refieren los mitos de origen del imperio incaico, entonces la tarea siguiente consiste en tratar de probar dicha asociación, para lo cual, sin embargo, conforme lo adelantamos, no contamos con datos directos e incontrovertibles.

En efecto, fuera de las alusiones a la existencia de la lengua, no disponemos en verdad de evidencias lingüísticas directas que puedan servirnos para realizar dicha probanza. No podemos sino lamentar, en este contexto, que el cronista Cobo no se haya dado el trabajo de consignar alguna muestra de la lengua, por mínima que ella fuera, de labios de don Alonso Topa Atau, nieto de Huaina Capac, quien según el mismo historiador "todavía se acordaba [...] de algunos vocablos della" ( $c f$. Cobo [1653] 1956: XII, III, 64). Solo quedaba entonces por examinar las palabras que, según el Inca Garcilaso, al no poder interpretarlas a partir de su quechua materno, las considera propias del "lenguaje particular", la mismas que se reducen a una lista de cerca de diecinueve piezas léxicas, la mayoría de ellas nombres propios (antropónimos y topónimos). La diligencia llevada a cabo con tal propósito probó que, en efecto, fuera de algunos vocablos explicables a partir del quechua o del aimara, el resto del corpus léxico garcilasiano parece acusar una procedencia distinta, que en este caso podría atribuirse al puquina ( $c f$. Cerrón-Palomino 2013: I-3).

\section{Identificación de la "lengua particular"}

Uno de las aportes más importantes efectuados por la investigación de los últimos decenios del siglo pasado en materia de prehistoria andina fue el esclarecimiento semántico del nombre étnico de colla para referir no a los pueblos de habla aimara, como se pensaba, sino a las unidades sociopolíticas de habla puquina ( $c f$. Julien 1983: cap. 2, Bouysse-Cassagne 1988: Parte I). De este modo cobraba sentido el hecho de que las fuentes coloniales hicieran alusión a collas y puquinas como pueblos, si no idénticos, muy vinculados entre sí, como ocurre por ejemplo en la obra del cronista indio de Lucanas, quien señala nada menos que "los poquina collas tambien fue casta de yngas" (cf. Guaman Poma [1615] 1936:85).

La restitución del nombre de <colla $>$ en los términos señalados se apoyaba en la identificación de cierto léxico que, al ser localizado en los textos de Oré, probaba su incuestionable procedencia puquina ( $c f$. Bouysse-Cassagne, op. cit., I, 57-58). Tales voces, convertidas luego en elementos diagnósticos de la presencia de la lengua, demarcando un territorio parcialmente coexistente con el del quechua y del aimara, serían nada menos que <capac> 'jefe', <iqui> 
'señor', < umi> 'señora', <coa> 'divinidad', la primera de las cuales, consignada como tal en quechua y como <capaca> en aimara, se consideraba hasta entonces propia de estas lenguas. Se podía entender ahora por qué, según las informaciones proporcionadas por las crónicas, los jefes collas se resistían a ser despojados del apelativo <capac> ( $c f$. Betanzos 1551: XX, fol. 49; Sarmiento de Gamboa [1572] 1965:[37], 242), que consideraban exclusivamente suyo. Del mismo modo, el adjetivo <collana > 'excelso, supremo, primero', desvinculado del etnónimo <colla $>$, y considerado de origen eminentemente quechua, dejaba traslucir esta vez su clara ascendencia puquina, exigiendo no solo la explicación de la asociación léxica involucrada sino también la del significado especial que había adquirido dentro del sistema de organización social y espacial del incario, sobre todo en oposición a < payana> 'segundo en el orden jerárquico', voz de origen aimara, a su turno erradamente etimologizada como quechua (cf. Cerrón-Palomino 2008:II-6).

De esta manera, quedaban sentadas las bases para el estudio destinado al rescate de la presencia de la lengua puquina en la historia de los incas. En tal sentido, los trabajos que se vienen desarrollando en dicha dirección han ido descubriendo de manera sorprendente el origen puquina de varios nombres propios e institucionales que hasta entonces eran asumidos como de origen quechua o aimara y cuya interpretación a partir de estas lenguas se hacía de manera completamente arbitraria.

Así ocurrió, por citar algunos ejemplos, en los casos de <Ayar >, <Manco >, $<$ Roca $>$, entre los nombres propios; y en los de <inca $>$, <layca $>,<$ tocri $>$, $<$ quiz>, <raymi>, entre los de orden institucional, para no mencionar nombres tan importantes como los de sus divinidades mayores como < Titi> e $<$ Inti $>$ (ver, para otros ejemplos, Cerrón-Palomino 2013:I-3). Asimismo, una vez aislada la raíz *puqi como el étimo de <puqui-na>, los nombres de los santuarios $<$ Poquencancha $>\mathrm{y}<$ Poquenpuquio $>$, localizados en el corazón de la metrópoli incaica, dejaban descubrir, debajo de su estructura de compuestos híbridos, la obvia atribución de posesión del elemento referido por el núcleo nominal (<cancha> 'cerco' y < puquio> 'manantial', vocablos compartidos por el quechua y el aimara) nada menos que a los integrantes del grupo étnico involucrado. De este modo, topónimos como los mencionados, alusivos a los puquinas, pero sobre todo aquellos que después serán identificados como portadores de un elemento claramente reconocido como propio de la lengua, servirán no solo para corroborar sino también para delimitar y precisar la presencia territorial de la lengua. Algunos de tales elementos léxicos claramente puquinas, llamados por ello "diagnósticos", y cuyo número ha ido incrementándose a medida que se han venido afinando las herramientas que permiten su identificación, son <paya $\sim$ baya $\sim$ huaya $>$ 'terreno en declive', <raque $\sim$ laque $>$ 'barranco', <chata llata $>$ 'cerro', <cachi> 'cerco', <para huara $>$ 'río', <quiru $\sim$ quira $>\sim$ quilla $>$ 'coca', <colli $\sim$ coñi $>$ 'ardiente', etc. 
De todos ellos, dos aparecen consignados en el vocabulario extraído de Oré (<chata-llata> 'cerros' y < para> 'río') y otros dos en el vocabulario de Bertonio ([1612] 1984: II, 141: <huaa-huaa> "cuesta abajo"; II, 298: <quiru-yqui> "el que ha enriquecido con el trato de la coca"); los dos restantes se dan, como elemento de un topónimo recurrente en el caso de <raque $\sim$ laque $>$ (así en $<$ Copo-raque $>$ y < Coa-laque $>$ ), y como epíteto en el caso del segundo (así, en $<$ Coñ-titi $>$, el nombre del dios supremo de origen lacustre, pero también los $<$ colli> de Moquegua).

En relación con la identificación de nombres asignables a la lengua, hay que señalar que, con ser magro el vocabulario de Oré, no es poco lo que se puede aprovechar de él en materia de reglas fonológicas, ya que afortunadamente algunas de éstas han podido inferirse de dicho corpus. Una de tales reglas es sin duda la tendencia hacia la lenición o suavización de ciertas consonantes, tal como lo mencionan Adelaar y van de Kerke (cf. art. cit::129), y como se ilustra en algunos de los ejemplos citados en el párrafo precedente. De esta manera se tienen: (a) $/ \mathrm{p} / \sim / \mathrm{b} / \sim / \mathrm{w} /$, como en la variación del elemento <paya $\sim$ baya $\sim$ huaya $>$ en topónimos como <Tutu-paya $>$ 'Cuesta grande', $<$ Molle-baya > 'Cuesta de molles' y < Titi-n-huaya $>$ 'Rampa del Sol'; (b) /t/ $/ \mathrm{r} /$, como el elemento <titi $\sim$ riti $>$ en $<$ Coñ-titi $>$ 'Sol ardiente' y en $<$ Paa-riti $>$ 'Dos Soles', respectivamente; y (c) $/ \check{c} / \sim / \lambda /$, como en $<$ Quimsa-chata $>$ 'Tres cerros', pero también en <Paa-llata $>$ 'Dos cerros'. Es más, el material de Oré puede ayudarnos asimismo en la identificación de elementos léxicos tras la constatación de que la lengua admitía grupos consonánticos iniciales del tipo $<$ st $>,<$ sc $>$ frecuentes en topónimos como < Estaca $>$ (registrado también en nombres de persona) y $<$ Escara $>$, que delatan la consabida vocal protética castellana, y cuyo significado todavía permanece huidizo, aunque el segundo puede glosarse tentativamente como 'sementera'.

De otro lado, y más allá de su registro documental, nuestro conocimiento del sistema fonológico de la lengua puede verse enriquecido también por la textura fónica con la que los topónimos fueron asimilados dentro del quechua o del aimara. Ciertamente, como observan Adelaar y van de Kerke, de los materiales de Oré no resulta claro, por ejemplo, que la lengua hiciera distinción entre el punto velar /k/ y el postvelar/q/, como lo hacen el quechua, el aimara y el uro; tampoco parece evidente que ella registrara laringalizadas (aspiradas y glotalizadas), igualmente presentes en los idiomas mencionados. No obstante, creemos que, tras la identificación de algunos elementos toponímicos asignables a la lengua, no parece haber duda de que tales distinciones también las hacía el puquina. Así, por un lado, el mismo registro del nombre < poque $>$ remite a /puqi/, a la par que < quiru $\sim$ quira $>$ sugiere $/ \mathrm{k} /$; pero, de otro lado, <quis > 'luna/ mes' remite a /khis/ (según testimonio del uro) y < capac $>$ lo hace a /qhapaq/, del mismo modo que <colli $>$ y $<$ chata $>$ sugieren /q'u $\lambda \mathrm{i} / \mathrm{y} /$ č $^{\prime}$ ata/, respectivamente, como lo evidencia el quechua de 
Moquegua. Ejemplos como éstos parecen demostrar, de manera convincente, que las distinciones hechas por tales elementos seguramente se daban en la lengua fuente; lo contrario significaría que las entidades receptoras, lejos de asimilarlas con sus recursos fónicos menos marcados, hubieran optado por sonidos más complejos, contraviniendo las reglas de acomodación fonética en casos de contacto idiomático.

\section{Atando cabos interdisciplinarios}

La tesis del origen lacustre de los incas, así como la de la identificación del "lenguaje secreto" de éstos con el puquina de los fundadores de Tiahuanaco, no es nueva. En efecto, así lo han venido sosteniendo algunos historiadores, entre ellos Bouysse-Cassagne (1987: cap. II, 1988: I), Espinoza Soriano (1987: cap. 2, 36-38), y más recientemente Hiltunen (1999: cap. IV, § $2.2,264)$. Apoyada en indicios de carácter histórico-documental, en el primer caso, y arqueológico en el segundo (ver, ahora, McEwan 2011), faltaba sin embargo la evidencia lingüística para que la hipótesis, reforzada por los datos provenientes de las otras dos disciplinas, reposara sobre bases más sólidas (cf. Cerrón-Palomino 2012:§§ 7.2-7.3). En las secciones precedentes creemos haber aportado precisamente el ingrediente lingüístico que hacía falta. Pero, además, últimamente, los estudios de genética parecen confirmar también la procedencia altiplánica de los incas míticos. En efecto, a tal conclusión, si bien tentativa, llega el profesor Ken-ichi Shinoda, del Museo Nacional de Naturaleza y Ciencia de Tokyo, en su estudio de ADN mitocondrial sobre la base del análisis comparativo de restos óseos de la antigua capital incaica y del altiplano, probando que, geográficamente, la población incaica debió proceder de los alrededores del gran lago Titicaca ( $c f$. Shinoda 2012). De esta manera, las evidencias provenientes de las disciplinas tanto humanísticas como naturales, particularmente la de la biología molecular, parecen confirmar la veridicción de los mitos de origen de los predecesores de los fundadores de la civilización incaica.

\section{A manera de conclusión}

En las secciones precedentes hemos tratado de sostener, en primer lugar, que los relatos míticos acerca de los orígenes de los incas recogidos por los cronistas, lejos de constituir narraciones desprovistas de coherencia argumental, pueden estar, en tanto saber colectivo almacenado en la memoria de los pueblos, y al margen de la cuestión de la impertinencia relativa a su verosimilitud ( $c f$. Ballón Aguirre 2006: cap. 4, § 1), henchidos de historicidad. En tal sentido, la ponencia busca llamar la atención de quienes, en ausencia de una versión escrita y carente de respaldo material, desautorizan de entrada los relatos transmitidos oralmente, por no ajustarse a las características de un 
discurso histórico occidental. En segundo lugar, y de manera más concreta, hemos intentado demostrar que los mitos del origen lacustre de los ancestros de los incas encuentran pleno respaldo histórico proveniente de las disciplinas afines de la historia, la arqueología y la lingüística, pero también de una ciencia natural como la genética. De esta manera, una hipótesis largamente acariciada, si bien hasta hace poco bastante controversial a falta de mayores evidencias, finalmente parece encontrar un sólido respaldo proveniente de las ciencias mencionadas, de las cuales la lingüística y la genética parecen tener la última palabra.

\section{Referencias}

Adelaar, Willem, Simon van de Kerke 2009. Puquina. En: Mily Creveles, Pieter Muysken (eds.). Lenguas de Bolivia. Tomo I: Ámbito andino, pp. 125-146. La Paz: Musef/Plural,

Ballón Aguirre, Enrique. 2006. Tradición oral peruana. Literaturas ancestrales y populares. Lima: Fondo Editorial de la PUCP, Tomo I.

Bauer, Brian S., Lukas C Kellet, Miriam Aráoz Silva. 2010. The Chanka. Archaeological Research in Andahuaylas (Apurimac), Peru. Los Angeles, UCLA: Cotsen Institute of Archaeology Press.

Bertonio, Ludovico. [1612] 1984. Vocabvlario de la lengua aymara. Cochabamba: CERES/ IFEA.

Betanzos, Juan Díez de. 1551. Suma y narración de los incas. Palma de Mallorca. Ms.

Bouysse-Cassagne, Thérese. 1987. La identidad aymara: aproximación histórica (siglo XV, siglo XVI). La Paz: Hisbol/ IFEA.

Bouysse-Cassagne, Thérèse. 1988. Lluvias y cenizas. Dos Pachacuti en la historia. La Paz : Hisbol.

Bouysse-Cassagne, Thérèse. 1991. Poblaciones humanas antiguas y actuales. En: Claude Dejoux, André Iltis (eds.). El lago Titicaca. Síntesis del conocimiento limnológico actual, pp. 481-498, 527-530 (bibliografía). La Paz: ORSTOM/HISBOL.

Cantos de Andrada, Rodrigo [1586] 1965. Relación de la Villa Rica de Oropesa y minas de Guancavelica. En: Marcos Jiménez de la Espada (ed.), Relaciones geográficas de Indias, I, pp. 303-309. Madrid: Ediciones Atlas.

Cerrón-Palomino, Rodolfo. 2008. Voces del Ande. Ensayos sobre onomástica andina. Lima: Fondo Editorial de la PUCP.

Cerrón-Palomino, Rodolfo 2012. Unravelling the enigma of the 'particular language' of the Incas. En: Paul Heggarty, David Beresford-Jones (eds.), Archaeology and Language in the Andes. Proceedings of the British Academy, pp. 265-294. Oxford: Oxford University Press.

Cerrón-Palomino, Rodolfo. 2013. Las lenguas de los incas. Frankfurt am Main: Peter Lang. 
Cerrón-Palomino, Rodolfo, Enrique Ballón Aguirre 2011. Chipaya. Léxico y etnotaxonomía. Lima: Fondo Editorial de la PUCP.

Cobo, Bernabé. [1653] 1956. Historia del Nuevo Mundo. Obras del P. Bernabé Cobo. Madrid: BAE, Ediciones Atlas. Tomos I-II.

De la Grasserie, Raoul. 1894. Langue Puquina. Leipzig: K.F. Koehler, Libraire-éditeur.

De la Viñaza, Conde [1892] 1977. Bibliografía española de lenguas indígenas de América. Madrid: Ediciones Atlas.

Duviols, Pierre. 1979. La guerra entre el Cuzco y los chanca: ¿historia o mito? Revista de la Universidad Complutense de Madrid 20: 117, 363-371.

Espinoza Soriano, Waldemar. 1987. Los incas. Economía, sociedad y estado en la era del Tahuantinsuyo. Lima: Amaru Editores.

Garcilaso de la Vega, Inca [1609] 1943. Comentarios Reales de los Incas. Buenos Aires: Emecé Editores S.A.

Gutiérrez Estévez, Manuel. 2001. Las diferencias contra la mitología. En: Miguel LeónPortilla, Manuel Gutiérrez Estévez, G.H. Gossen (eds.). Motivos de la antropología Americanista, pp. 327-365. México: F. C. E.

Guaman Poma de Ayala, Felipe [1615] 1936. Nueva corónica y buen gobierno. Paris: Institut d'Ethnologie.

Hardman de Bautista, Martha J. [1966] 1975. El jaqaru, el kawki y el aymara. Actas del Simposio de Montevideo, pp. 186-192. México: Editorial Galache.

Hiltunen, Juha H. 1999. Ancient Kings of Peru. Helsinki: Suomen Historiallinen Seura.

Julien, Catherine J. 1983. Hatunqolla: a View of Inca Rule from the Lake Titicaca Region. Berkeley: University of California Press.

McEwan, Gordon. 2011. Indicators of Possible Driving Forces for the Spread of Quechua and Aymara as Reflected in the Archaeology of Cuzco. En Paul Heggarty, David Beresford-Jones (eds.). Archaeology and Language in the Andes. Proceedings of the British Academy, pp. 247-263.Oxford: Oxford University Press.

Murúa, Martín de. [1613] 1987. Historia general del Perú. Madrid: Historia 16.

Oré, Jerónimo de 1607. Ritvale sev Manvuale Pervanvm [...]. Neapoli: Jacobum Carlinum et Constantinum Vitalem.

Parker, Gary J. 1972. Falacias y verdades acerca del quechua. En Escobar, Alberto (ed.). El reto del multilingüismo en el Perú, pp. 111-121. Lima: Instituto de Estudios Peruanos.

Ponce Sanginés, Carlos, Johan Reinhard.1992. Exploraciones arqueológicas subacuáticas en el Lago Titikaka: Informe científico. La Paz: Editorial La Palabra Producciones.

Ramos Gavilán, Alonso. [1621] 1988. Historia del Santuario de Nuestra Señora de Copacabana. Lima: Edición de Ignacio Prado Pastor.

Santillana, Julián I. 2002. Chancas e incas: un nuevo examen. En Javier Flores Espinoza, Rafael Varón Gabai (eds.). El hombre y los Andes. Homenaje a Franklin Pease G.Y., Tomo II, pp. 553-566. Lima: Fondo Editorial de la PUCP. 
Sarmiento de Gamboa, Pedro. [1572] 1965. Historia Indica. Madrid: BAE, Ediciones Atlas, Tomo CXXXV, pp. 195-279.

Shinoda, Ken-ichi. 2012. Tracing the Origins of Inka People through Ancient DNA Analysis. En Izumi Shimada (ed.). Diversity and Unity in the Inka Empire: Current Issues and Visions. Tokyo: Tokai University Press. Por aparecer.

Stark, Louisa. 1972. Machaj Suyay: Secret Language of the Callahuayas. Papers in Andean Linguistics 1: 2, pp. 199-227.

Toledo, Francisco de. [1575] 1989. Disposiciones gubernativas para el virreinato del Perú, Tomo II. Sevilla: C.S.I.C.

Torero, Alfredo. [1970] 1972. Lingüística e historia de la sociedad andina. En Alberto Escobar (ed.). El reto del multilingüismo en el Perú, pp. 51-106. Lima: Instituto de Estudios Peruanos.

Torero, Alfredo. 1987. Lenguas y pueblos altiplánicos en torno al siglo XVI. Revista Andina 10, pp. 329-405 (con debate).

Zuidema, Tom R. 1977. Mito e historia en el antiguo Perú. Allpanchik 10, 15-52.

Data recebimento: $16 / 08 / 2012$

Data aceite: $27 / 05 / 2013$ 